\title{
Extending Networks of Collaboration to Multi-market Oligopolies
}

\author{
Pascal Billand ${ }^{1, *}$, Christophe Bravard ${ }^{1}$, Subhadip Chakrabarti ${ }^{2}$, and Sudipta Sarangi ${ }^{3}$ \\ ${ }^{1}$ Pascal Billand, University Jean Monnet, Gate Lyon-Saint-Etienne, \\ 6 rue basse des rives 42023 Saint-Etienne, France \\ pascal.billandauniv-s-etienne.fr \\ ${ }^{2}$ Subhadip Chakrabarti, School of Management and Economics, Queen's University Belfast, \\ Northern Ireland, United Kingdom \\ ${ }^{3}$ Sudipta Sarangi, Department of Economics, Louisiana State University, \\ Baton Rouge, LA 70803, USA
}

\begin{abstract}
In this article, we extend the Goyal and Joshi's model (2003) of network of collaboration in oligopoly to multi-market situations. We examine the incentive of firms to form links and the architectures of the resulting networks in this setting. We also present some results on efficient networks.
\end{abstract}

Keywords: collaborative networks, multimarket oligopolies.

\section{Introduction}

Research collaborations among firms take a variety of forms, such as joint ventures, technology sharing or joint $\mathrm{R} \& \mathrm{D}$, and can play a prominent role in economic performance (Hagedoorn, 2006). These collaborations are often bilateral and non exclusive, and form a network of collaborative links between firms. Goyal and Joshi (GJ, 2003) develop a model of network formation between firms which compete on one market in order to predict the architectures of the networks that should emerge and examine to what extent these networks are socially efficient. Now it is often the case that firms compete in few markets. In a seminal paper, Bullow et al. (1985) examine how the introduction of multimarket competition can produce quite unexpected results. In this paper, we ask what happens to equilibrium and efficient networks when we introduce multimarket competition in the GJ's model of formation of collaborative networks. We assume for purposes of simplicity, a heterogeneous product market, with linear demand curves and quadratic cost functions, where multimarket competitors can form quality products enhancing collaborative links on one market. Concerning equilibrium networks it turns out that as in GJ (2003), equilibrium networks have a dominant group architecture, i.e. a group of firms are linked to each other while other firms have no links at all. We show that this result follows from the fact that our collaborative multimarket game qualifies as playing the field games (Goyal and Joshi, 2006), with payoff function satisfying convexity in own links as well as the strategic substitutes property with regard to quantities. However, using Bullow et al. (1985)

\footnotetext{
${ }^{*}$ Corresponding author.
} 
analysis, we show that contrary to the model of GJ (2003) there exist situations where competitors do not form collaborative links in order to increase the quality of their products even if these links have no costs. This result follows from the fact that there are joint diseconomies across markets and goods produced by competing firms are strategic substitutes. It illustrates how the intermarket effect plays a key role in the incentive of firms to collaborate.

With regard to efficient networks, though we cannot arrive at a precise characterization of these networks, we can derive some interesting properties of such networks and restrict the set of networks that are efficient into a small group. More precisely, for four firms or more, efficient networks have only one component (or one group). Moreover in an efficient network the diameter of the component is very low, since the geodesic distance between two connected firms in the component cannot exceed two.

The rest of the paper proceeds as follows. Section 2 introduces the model and discusses the notation and terminology. Section 3 examines equilibrium networks, while Sections 4 deals with efficient networks ${ }^{1}$. Section 5 concludes.

\section{The Framework}

\subsection{The Multi-market Cournot Model}

Suppose there are $\mathrm{n}$ firms indexed by $\mathrm{i}=1,2, \ldots, \mathrm{n}($ where $\mathrm{n}>2$ ) that compete a la Cournot in two inter-related markets $\mathrm{A}$ and $\mathrm{B}$. We denote by $\mathrm{q}_{\mathrm{i}}$ and $\mathrm{Q}_{\mathrm{i}}$ the quantities sold by firm $i$ on markets $A$ and $B$ respectively, and by $p_{i}$ and $P_{i}$ the prices of firm i's products on these markets. Focusing on the most interesting case, we suppose that competitors' products are strategic substitutes and there are diseconomies of scope across markets. More specifically, demand in markets A and B for firm i are respectively given by

$$
p_{i}=\alpha_{i}-q_{i}-\sum_{j \neq i} q_{j}, P_{i}=\beta_{i}-Q_{i}-\sum_{j \neq i} Q_{j}
$$

And the cost function of a firm $i$ is given by

$$
C_{i}\left(q_{i}, Q_{i}\right)=\frac{1}{2}\left(q_{i}+Q_{i}\right)^{2}
$$

\subsection{Quality Improving Links and Collaborative Networks}

We assume that firms can improve the quality of their products via collaborative links in market A. More specifically, we suppose that if a firm has formed $\mathrm{k}$ links, then we have

with $\gamma_{0}, \gamma \in \mathrm{IR}_{+}$.

$$
\alpha_{i}=\gamma_{0}+\gamma \cdot k
$$

${ }^{1}$ The detailed proofs of the results can be found in a complete version of the paper at the following address: http://portail.univ-st-etienne.fr/bienvenue/recherche/working-papers-creuset2010-285615.kjsp?RH=0611171526yr. 
It is reasonable to assume that $\gamma_{0}>\gamma$. For reasons that will be clear later, we assume $\gamma_{0}$ is sufficiently large compared to $\gamma$, namely,

$$
\gamma_{0}>\left(\frac{(n-1)^{2}}{2}\right) \cdot \gamma
$$

A collaborative network $\mathrm{g}$ is a list of pairs of firms who are linked to each other. For simplicity, we denote the link between $i$ and $j$ (where $i \neq j$ ) by $i j$, so $i j \in g$ indicates that $\mathrm{i}$ and $\mathrm{j}$ are linked in the network $\mathrm{g}$.

Let $g^{N}$ be the set of all subsets of $\mathrm{N}$ of size 2 . The network $\mathrm{g}^{\mathrm{N}}$ is referred to as the complete network. The set $\mathrm{G}=\left\{\mathrm{g} \subset \mathrm{g}^{\mathrm{N}}\right\}$ denotes the set of all possible networks on $\mathrm{N}$. A network in which there are no links is called an empty network and is denoted by $g^{0}$. We let $g+i j$ denote the network formed by adding the link ij to the network $g$, and $\mathrm{g}$ - ij denote the network formed by deleting the link ij from the network $\mathrm{g}$. A network profits function $\pi_{\mathrm{I}}: \mathrm{G} \rightarrow \mathrm{R}_{+}$assigns some profits to firm $\mathrm{i}$ by virtue of being part of a network. Let $\pi=\left(\pi_{1}, \pi_{1}, \ldots, \pi_{n}\right)$ denote the vector of profits functions. Then $\pi$ combined with $\mathrm{N}$ defines a network game.

A firm i's neighborhood $N_{i}(g)$ is given by $\{j \in N \backslash\{i\} \mid i j \in g$ and its cardinality is given by $\eta_{i}(g)=|N i(g)|$. $\eta_{i}(g)$ is called the degree of firm i in network $g$. We also define $\mathrm{N}(\mathrm{g})$ as the set of firms that have at least one link. Let $\eta(\mathrm{g})=\# \mathrm{~N}(\mathrm{~g})$ with the convention that if $\mathrm{N}(\mathrm{g})=\varnothing$, we let $\eta(\mathrm{g})=1$.

We define as $L_{i}(g)=\{i j \in g\}$ the set of links in which firm $i$ is involved. Let $\lambda(g)=$ $1 / 2\left(\sum \eta_{\mathrm{i}}(\mathrm{g})\right)$ be the total number of links in a network $\mathrm{g}$.

For any $\mathrm{h} \subset \mathrm{g}$, let $\mathrm{g}-\mathrm{h}$ denotes the network formed by deleting the set of links $\mathrm{h}$ from the network $g$. Similarly, for $h \subset g^{N} \backslash g, g+h$ denotes the network formed by adding the link set $\mathrm{h}$ to the network $\mathrm{g}$. Moreover we define $\mathrm{g}_{-\mathrm{i}}=\mathrm{g} \backslash \mathrm{Li}(\mathrm{g})$ the resulting network once we remove firm $\mathrm{i}$ and all his links from the network $\mathrm{g}$. A network $\mathrm{g}$ is regular if each firm has the same number of links. A path in $g$ connecting $\mathrm{i}$ and $\mathrm{j}$ is a set of distinct firms $\left\{i_{1}, i_{2}, \ldots, i_{p}\right)$, with $p>2$, such that $i_{1}=i, i_{p}=j$, and $\left\{i_{1} i_{2}, i_{2} i_{3}, \ldots\right.$, $\left.i_{p-1} i_{p}\right\} \in g$. We refer to the number of links on this path, here $p-1$, as the length of the path. We say $i$ and $j$ are connected to each other if a path exists between them and they are disconnected otherwise. The number of links on the shortest path between two distinct firms $\mathrm{i}$ and $\mathrm{j}$ is called the geodesic distance between $\mathrm{i}$ and $\mathrm{j}$. The network $\mathrm{g}^{\prime} \subset \mathrm{g}$ is a component of $\mathrm{g}$ if $\mathrm{N}\left(\mathrm{g}^{\prime}\right) \geq 2$ and for all $\mathrm{i} \in \mathrm{N}\left(\mathrm{g}^{\prime}\right)$ and $\mathrm{j} \in \mathrm{N}\left(\mathrm{g}^{\prime}\right), \mathrm{i} \neq \mathrm{j}$, there exists a path in $g^{\prime}$ connecting $i$ and $j$ and for any $i \in N\left(g^{\prime}\right)$ and $j \in N(g), i j \in g$ implies $\mathrm{ij} \in \mathrm{g}$ '. In other words, a component is simply a maximally connected subnetwork of $\mathrm{g}$. We denote the set of network components of the network $\mathrm{g}$ by $\mathrm{C}(\mathrm{g})$. The set of firms that are not connected in the network $g$ are connected in the set of (fully) disconnected firms in $\mathrm{g}$ denoted by

$$
N_{0}(g)=N \backslash N(g)=\left\{i \in N \quad \mid N_{i}(g)=\varnothing\right\}
$$

Such firms are known as singletons. A component g' $\subset \mathrm{g}$ is complete if for all distinct $\mathrm{i} j \in \mathrm{N}\left(\mathrm{g}^{\prime}\right), \mathrm{ij} \in \mathrm{g}$. A component $\mathrm{g}^{\prime} \subset \mathrm{g}$ is regular if for all distinct $\mathrm{i}, \mathrm{j} \in \mathrm{N}\left(\mathrm{g}^{\prime}\right)$, $\eta_{\mathrm{i}}(\mathrm{g})=\eta_{\mathrm{j}}(\mathrm{g})$. The dominant group architecture $\mathrm{g}^{\mathrm{k}}$ is characterized by one complete non-singleton component with $\mathrm{k}>2$ firms and $\mathrm{n}-\mathrm{k}$ singletons. 


\subsection{Equilibrium and Efficient Networks}

A network $\mathrm{g}$ is a pairwise equilibrium network with regard to a profile of profits functions $\pi=\left(\pi_{1}, \pi_{2}, \ldots, \pi_{\mathrm{n}}\right)$ if

(a) for all i and $\mathrm{h} \subset \mathrm{L}_{\mathrm{i}}(\mathrm{g}), \pi_{\mathrm{i}}(\mathrm{g})>\pi_{\mathrm{i}}(\mathrm{g}-\mathrm{h})$, and

(b) for all $\mathrm{i}$ and $\mathrm{ij} \notin \mathrm{g}$, if $\pi_{\mathrm{i}}(\mathrm{g}+\mathrm{ij})>\pi_{\mathrm{i}}(\mathrm{g})$ then $\pi_{\mathrm{j}}(\mathrm{g}+\mathrm{ij})<\pi_{\mathrm{j}}(\mathrm{g})$.

For any network $\mathrm{g}$, and $\mathrm{h} \subset \mathrm{g}{ }^{\mathrm{N}} \backslash \mathrm{g}$, we denote the marginal benefit of link formation by $\Delta \pi_{\mathrm{i}}(\mathrm{g}, \mathrm{h})=\pi_{\mathrm{i}}(\mathrm{g}+\mathrm{h})-\pi_{\mathrm{i}}(\mathrm{g})$. Obviously, for a pairwise equilibrium network, $\Delta \pi_{\mathrm{i}}(\mathrm{g}-$ $\mathrm{h}, \mathrm{h})>0$ for all $\mathrm{h} \subset \mathrm{Li}(\mathrm{g})$, and for all $\mathrm{ij} \notin \mathrm{g}$, if $\Delta \pi_{\mathrm{i}}(\mathrm{g}, \mathrm{ij})>0$, then $\Delta \pi_{\mathrm{j}}(\mathrm{g}, \mathrm{ij})<0$.

Next, we define efficient networks. Consider a welfare function $\mathrm{W}$ given by sum of payoffs of all the firms, i.e. $\mathrm{W}(\mathrm{g})=\sum_{\mathrm{i} \in \mathrm{N}} \pi_{\mathrm{i}}(\mathrm{g})$. A network $\mathrm{g}$ ' is efficient if it maximizes the welfare function, that is $\mathrm{W}\left(\mathrm{g}^{\prime}\right)>\mathrm{W}(\mathrm{g})$ for all $\mathrm{g} \neq \mathrm{g}^{\prime}$. For any network $\mathrm{g}$, and $\mathrm{h} \subset \mathrm{g}^{\mathrm{N}} \backslash \mathrm{g}$, we denote the marginal change in welfare as a result of link formation by $\Delta \mathrm{W}(\mathrm{g}, \mathrm{h})=\mathrm{W}(\mathrm{g}+\mathrm{h})-\mathrm{W}(\mathrm{g})$.

\section{Characterization of Equilibrium Networks}

While the payoff functions are quite complicated, this game has features that were analyzed by Goyal and Joshi (2006). We will devote some space to reproducing their definitions and terminology.

Definition 1. A network game is called playing the field game if the payoff of firm i is a function of her degree, $\eta_{\mathrm{i}}(\mathrm{g})$, and the total number of links formed by the other firms, $\lambda\left(\mathrm{g}_{-\mathrm{i}}\right)$, namely,

$$
\pi_{i}(g)=\Phi\left(\eta_{i}(g), \lambda\left(g_{-i}\right)\right) .
$$

Definition 2. The payoff function $\Phi$ is convex in its own links if the marginal returns $\Phi(\mathrm{k}+1, \mathrm{l})-\Phi(\mathrm{k}, \mathrm{l})$ is strictly increasing in $\mathrm{k}$.

Definition 3. Suppose l' $>1$. The payoff function $\Phi$ satisfies the strategic substitutes property if $\Phi\left(\mathrm{k}+1, \mathrm{l}^{\prime}\right)-\Phi\left(\mathrm{k}, \mathrm{l}^{\prime}\right)<\Phi(\mathrm{k}+1, \mathrm{l})-\Phi(\mathrm{k}, \mathrm{l})$.

The next lemma is a reproduction of Proposition 3.1 of Goyal and Joshi (2006).

Lemma 1. For a playing the field game, if the payoff function satisfies convexity in own links and the strategic substitutes property, then a pairwise equilibrium network always exists. Furthermore, a pairwise equilibrium network is either complete or empty or has the dominant group architecture.

It is easy to check that the collaborative multimarket game qualifies as playing the field game. Furthermore, the payoff function satisfies convexity in own links as well as the strategic substitutes property. In fact, if we define

$$
\Delta(k, l)=\Phi(k+1, l)-\Phi(k, l),
$$


then we have

$$
\frac{\partial \Delta(k, l)}{\partial k}=\frac{2 \gamma^{2}\left(11 n^{4}+44 n^{3}-6 n^{2}-100 n+83\right)}{18(1+n)^{2}(3+n)^{2}}>0
$$

and

$$
\frac{\partial \Delta(k, l)}{\partial l}=\frac{2 \gamma^{2}\left(22 n^{3}+102 n^{2}+66 n-158\right)}{18(1+n)^{2}(3+n)^{2}}<0
$$

Therefore, applying Lemma 1, we get the following corollary.

Corollary 1. The pairwise equilibrium network is either complete or empty or has a dominant group architecture.

Few remarks are in order here.

Remark 1. There are some surprising implications of this result. In the one-market Cournot model of GJ (2003), the dominant group architecture emerges if there are substantial link formation costs. Hence, introducing competition in additional markets has the same effect as introducing link formation costs.

Remark 2. It is easy to show using BGK (1985) analysis that the empty network can be a pairwise equilibrium network when costs of forming links are null. The intuition behind this fact is as follows: the formation of a link by firms $\mathrm{i}$ and $\mathrm{j}$ in market $\mathrm{A}$ enhances the quality of their product in this market and leads these firms to produce more for this market. Due to joint diseconomies across markets this reduces marginal profitability for these firms associated with a unit of production in market B and induces these firms to reduce their quantities on this market. Because of strategic substitutability, rival firms will increase their quantities on market B and this induces certainly a loss in market B, and possibly an overall loss for firms $\mathrm{i}$ and $\mathrm{j}$.

Remark 3. When the cost function exhibits economies of scope, there is no tension across markets anymore, that is the formation of a link by firms $i$ and $j$ in market $A$ leads these firms to enhance the quantities produced on both markets at equilibrium.

As a result the profits of these firms increase. It follows that when costs of forming links are null, the complete network is always the only equilibrium network. Thus we obtain the same result as in the Goyal and Joshi model where firms compete on one market only.

\section{Characterization of Efficient Networks}

In this section, we shall discuss efficient networks. While we do not obtain an exact characterization of efficient networks, we can identify certain properties of such networks. Consider the welfare effect of link formation between two arbitrary firms $\mathrm{i}$ and $\mathrm{k}$ in a network $\mathrm{g}$. This effect is given by 


$$
\left.\Delta W(g, i k)=k^{\prime}\left(\alpha_{i}+\alpha_{K}-\frac{\tau^{\prime}}{n} \sum_{l \pm i, k} \alpha_{l}+\Lambda^{\prime}\right)\right)-2 c
$$

where $\tau^{\prime}>0, \mathrm{k}^{\prime}>0$, and $\Lambda^{\prime}$ are constants independent of network structure. $\tau^{\prime}$ has an upper bound less than 11 (at $n=2$, its value is 10.79) and is strictly decreasing in $n$. It has a lower bound of 2 and converges asymptotically to 2 . It is important to note that at $n=4, \tau^{\prime}=3.5$. For the discussion that follows, let us assume $n \geq 3$.

Lemma 2. (i) For any network $g$ and firm i such that ik, im $\notin g$ and $\eta_{m}(g)>\eta_{k}(g)$, $\Delta \mathrm{W}(\mathrm{g}+\mathrm{ik}, \mathrm{im})>\Delta \mathrm{W}(\mathrm{g}, \mathrm{ik})$, (ii) If $\eta_{\mathrm{m}}(\mathrm{g})=\eta_{\mathrm{k}}(\mathrm{g})$, but $\mathrm{n} \geq 4, \Delta \mathrm{W}(\mathrm{g}+\mathrm{ik}, \mathrm{im})>\Delta \mathrm{W}(\mathrm{g}$, ik) as well.

Proof. (i) Starting from an arbitrary network g with ik, im $\notin$ g. Suppose firm i and k form a link. The increase in welfare is proportional to:

$$
\begin{aligned}
& \frac{\Delta W(g, i k)}{k^{\prime}}=2 \gamma_{0}+\gamma\left(\eta_{i}(g)+\eta_{k}(g)\right) \\
& -\frac{\tau^{\prime}}{n}\left((n-2) \gamma_{0}+\gamma \sum_{l \pm i, k, m} \eta_{l}(g)+\eta_{m}(g)\right)+\Lambda^{\prime}-\frac{2 c}{k^{\prime}}
\end{aligned}
$$

Suppose then that firms $\mathrm{i}$ and $\mathrm{m}$ form a link. The increase in social welfare is proportional to

$$
\left.\frac{\Delta W(g+i k, i m)}{k^{\prime}}=\frac{\Delta W(g, i k)}{k^{\prime}}+\gamma+\left(1+\frac{\tau^{\prime}}{n}\right)\left(\eta_{m}(g)-\eta_{k}(g)-1\right)\right)
$$

Now, since $\eta_{\mathrm{m}}(\mathrm{g}) \geq \eta_{\mathrm{k}}(\mathrm{g})+1$, this expression is positive, completing the proof.

(ii) We have

$$
\frac{\Delta W(g+i k, i m)}{k^{\prime}}=\frac{\Delta W(g, i k)}{k^{\prime}}+\chi\left(1-\frac{\tau^{\prime}}{n}\right)
$$

Since $\tau^{\prime}=3.5$ for $\mathrm{n}=4, \tau^{\prime} / \mathrm{n}<1$. Furthermore, $\tau^{\prime}$ and hence $\tau^{\prime} / \mathrm{n}$ are strictly decreasing in $n$, therefore $\tau$ ' $/ \mathrm{n}<1$ for all $n>4$. Hence it follows that in all cases we have

$$
\frac{\Delta W(g+i k, i m)}{k^{\prime}}>\frac{\Delta W(g, i k)}{k^{\prime}}
$$

The following lemma plays a key role in the results that follow.

Lemma 3. For any efficient network $g$, if $i j \in g$ and $i k \notin g$, then $\eta_{j}(g) \geq \eta_{k}(g)$. If $\mathrm{n} \geq 4$, then $\eta_{\mathrm{j}}(\mathrm{g})>\eta_{\mathrm{k}}(\mathrm{g})$.

Proof. Suppose there exists an efficient network $\mathrm{g}$ and $\mathrm{ij} \in \mathrm{g}$ and $\mathrm{ik} \notin \mathrm{g}$. Then, $\Delta \mathrm{W}(\mathrm{g}-\mathrm{ij}, \mathrm{ij})>0$. Suppose, towards a contradiction, $\eta_{\mathrm{k}}(\mathrm{g})>\eta_{\mathrm{j}}(\mathrm{g})$. This implies by 
Lemma 2 that $\Delta \mathrm{W}(\mathrm{g}, \mathrm{ik})>0$ contradicting that $\mathrm{g}$ is efficient. Hence, for all $\mathrm{k}$ such that ik $\notin \mathrm{g}, \eta_{\mathrm{k}}(\mathrm{g})<=\eta_{\mathrm{j}}(\mathrm{g})$.

Next let $\eta_{j}(g)=\eta_{k}(g)$ and $n \geq 4$. Again, $\Delta W(g$, ik $)>\Delta W(g-i j, i j)>0$ which contradicts that $\mathrm{g}$ is efficient. Therefore, $\eta_{\mathrm{k}}(\mathrm{g})<\eta_{\mathrm{j}}(\mathrm{g})$.

The proposition below sets forth properties that characterize efficient networks.

Proposition 1. (i) If $n \geq 4$, then the efficient network cannot consist of more than one component, (ii) the geodesic distance between any two connected firms in a efficient network is less than or equal to 2 .

Proof. (i) Suppose $\mathrm{h}_{1}, \mathrm{~h}_{2} \in \mathrm{C}$ (g) where $\mathrm{g}$ is an efficient network and $\mathrm{ij} \in \mathrm{h}_{1}$ and $\mathrm{kl} \in \mathrm{h}_{2}$. Now, $i$ is linked to $j$ and not to $k$ which implies using Lemma $3, \eta_{j}(g)>\eta_{k}(g)$. But 1 is linked to $\mathrm{k}$ but not to $\mathrm{j}$ which implies $\eta_{\mathrm{k}}(\mathrm{g})>\eta_{\mathrm{j}}(\mathrm{g})$. Hence, we arrive at a contradiction.

(ii) Take two firms $i$ and $j$ such that $i$ and $j$ belong to $N(h)$ where $h \in C(g)$. Hence, a path exists between $i$ and $j$. Suppose the shortest path is $\left\{i_{1} i_{2}, i_{2} i_{3}, \ldots, i_{p-1} i_{p}\right\}$, where $i_{1}$ $=i$ and $i_{p}=j$, and $p \geq 4$. $i_{1}$ is linked to $i_{2}$, but $i_{1}$ is not linked to $i_{3} ; i_{2}$ is linked to $i_{3}$ but $\mathrm{i}_{3}$ is not linked to $\mathrm{i}_{2}$. Hence, from Lemma 3 , we get both $\eta_{\mathrm{i} 2}(\mathrm{~g})>\eta_{\mathrm{i} 3}(\mathrm{~g})$ and $\eta_{\mathrm{i} 3}(\mathrm{~g})>$ $\eta_{\mathrm{i} 2}(\mathrm{~g})$. A contradiction.

Remark. It is noteworthy that pairwise equilibrium and efficient architectures do not coincide. Indeed, among non empty and non complete networks, while only networks with a complete component can be pairwise equilibrium, this is no longer true for efficient networks. Thus by contrast with pairwise equilibrium networks, in efficient networks firms who have formed links can be very asymmetric. Think for instance to a network where the component has a star architecture, that is one firm, say i has formed links with all other firms of the component while the latter have formed links only with firm $i$.

\section{Conclusion}

The dynamics of multi-market oligopolies first discussed in Bulow et al. (1985) can upset many results, which would hold in isolated oligopoly markets. Here we take the situation of collaborative link formation among Cournot oligopolists. The results that a complete network materializes in equilibrium when costs of links are null, no longer holds once we introduce multimarket competition. With positive link formation costs efficient networks have the very interesting feature that they consist of only one component with a very low diameter. An exact characterization of efficient networks in our framework, or more broadly in playing the field games, is an open question.

\section{References}

1. Bulow, J.I., Geanakopolos, J.D., Klemperer, P.D.: Multimarket Oligopoly: Strategic Substitutes and Complements. The Journal of Political Economy (1985)

2. Bernheim, B.D., Whinston, M.D.: Multimarket Contact and Collusive Behavior. Rand Journal of Economics 21, 1-26 (1996) 
3. Billand, P., Bravard, C., Chakrabarti, S., Sarangi, S.: Corporate Espionage, Working Paper (2010)

4. Dixit, A.: A Model of Duopoly Suggesting a Theory of Entry Barriers. Bell Journal of Economics 10, 20-32 (1979)

5. Chakrabarti, S., Haller, H.: An Analysis of Advertising Wars, Manchester School (2010) (forthcoming)

6. Goyal, G., Joshi, S.: Networks of Collaboration in Oligopoly. Games and Economic Behavior 43, 57-85 (2003)

7. Goyal, G., Joshi, S.: Unequal Connections. International Journal of Game Theory 34, 319349 (2006)

8. Jackson, M., Wolinsky, A.: A Strategic Model of Social and Economic Networks. Journal of Economic Theory 71, 44-74 (1996)

9. Vives, X.: Oligopoly Pricing: Old Ideas and New Tools. The MIT Press, Cambridge (1999) 